Review

\title{
The Role of G Protein-coupled Receptor Kinases in Cancer
}

\author{
Shan Yu1 ${ }^{1}$ Litao Sun², Yufei Jiao ${ }^{3}$, Leo Tsz On Lee ${ }^{1 凶}$ \\ 1. Centre of Reproduction Development and Aging, Faculty of Health Sciences, University of Macau, Taipa, Macau \\ 2. Department of Ultrasound, The Secondary Affiliated Hospital of Harbin Medical University, Harbin, China \\ 3. Department of Pathology, The Secondary Affiliated Hospital of Harbin Medical University, Harbin, China \\ $\triangle$ Corresponding author: Leo T.O. Lee, Centre of Reproduction, Development and Aging, Faculty of Health Sciences, University of Macau, Taipa, Macau, \\ China; E-mail: LTOLee@umac.mo \\ (C) Ivyspring International Publisher. This is an open access article distributed under the terms of the Creative Commons Attribution (CC BY-NC) license \\ (https://creativecommons.org/licenses/by-nc/4.0/). See http://ivyspring.com/terms for full terms and conditions.
}

Received: 2017.09.19; Accepted: 2017.11.17; Published: 2018.02.05

\begin{abstract}
G protein-coupled receptors (GPCRs) are the largest family of plasma membrane receptors. Emerging evidence demonstrates that signaling through GPCRs affects numerous aspects of cancer biology such as vascular remolding, invasion, and migration. Therefore, development of GPCR-targeted drugs could provide a new therapeutic strategy to treating a variety of cancers. G protein-coupled receptor kinases (GRKs) modulate GPCR signaling by interacting with the ligand-activated GPCR and phosphorylating its intracellular domain. This phosphorylation initiates receptor desensitization and internalization, which inhibits downstream signaling pathways related to cancer progression. GRKs can also regulate non-GPCR substrates, resulting in the modulation of a different set of pathophysiological pathways. In this review, we will discuss the role of GRKs in modulating cell signaling and cancer progression, as well as the therapeutic potential of targeting GRKs.
\end{abstract}

Key words: G protein-coupled receptor (GPCR), G protein-coupled receptor kinase (GRK), Cancer, Cell signaling

\section{Introduction}

More than 700 genes have been identified as $\mathrm{G}$ protein-coupled receptors (GPCRs), which form the largest protein superfamily in the human genome [1]. GPCRs play key roles in mediating a wide variety of physiological events, from hormonal responses to sensory modulation (vision, olfaction, and taste) [2,3]. GPCR-targeting drugs are used to treat many diseases. Over $40 \%$ of all FDA approved drugs are aimed at targeting GPCRs or their related pathways [4]. GPCRs are now being used as early diagnosis biomarkers for cancer, as they play integral roles in regulating and activating cancer-associated signaling pathways [5,6]. Though GPCRs represent a growing share of all new anticancer therapies, "druggable" GPCRs represent only a small subset of receptors from this superfamily $[5,7]$. This is mainly due to drug resistance, as studies that have used short- and long-term exposure to GPCR-targeting drugs have observed receptor desensitization $[5,8,9]$. Therefore, the pharmacological potential for GPCRs and their downstream regulators requires further investigation in order to further develop therapies that can efficiently target cell signaling pathways in cancer [6].

GPCR signaling generally results in the transmission of amplified signals throughout the cell, and hyperactivation of these receptors may result in loss of normal cell physiological properties. There are several mechanisms including GTP hydrolysis, second messenger related protein kinases (e.g., PKA and PKC), G-protein-coupled receptor kinases (GRKs), and arrestins that prevent hyperactivation of GPCR signaling. However, the most important mechanism of terminating GPCR hyperactivation is GRK-mediated phosphorylation. Upon liganddependent receptor activation, GRK phosphorylates its target GPCR to prevent excessive cellular signaling. The details of this GPCR termination mechanism will be discussed in our review. Because GRKs act as negative regulators of GPCR activity, it has been suggested that they may play a role in cancer 
progression by regulating cell proliferation, migration, apoptosis, invasion, and tumor vascularization in a cell type-dependent manner [10-14]. Therefore, a complete understanding of their role in GPCR signaling is of high clinical importance. In this article, we will review current research linking GRKs to various aspects of cancer biology and discuss the therapeutic potential of targeting GRKs.

\section{Role of GRKs in GPCR signaling pathway}

\section{GPCR signaling pathway}

GPCRs serve as the interface between intracellular and extracellular environments. Receptors of this family are characterized by seven highly hydrophobic transmembrane helix structures. Stimuli, such as photons, small chemicals, ions, or protein ligands induce conformational changes in GPCR, which translates into cell signaling responses by activating coupled trimeric $\mathrm{G}$ protein complexes [15]. Based on sequence and structural similarity, GPCRs are classified into five subfamilies, namely rhodopsin, secretin, glutamate, adhesion, and frizzled [1]. The core structure of each GPCR can be divided into three domains: the extracellular region (ECR), which includes the $\mathrm{N}$-terminus and three extracellular loops, the transmembrane region (TM), which includes seven $\alpha$-helices, and the intracellular region
(ICR) that contains three intracellular loops, an intracellular amphipathic helix, and the C-terminus [16]. Generally, the functional role of the ECR is to initiate binding of specific ligands. The TM region forms the receptor core structure, which is important for transducing extracellular stimulus through conformational changes. The TM region may also be involved in ligand binding in the majority of GPCRs. The ICR interacts with coupled G proteins, which are activated through conformational changes, and transduce downstream intracellular signaling [16].

Upon induction of conformational changes, GPCRs mediate signaling through $G$ protein heterotrimers (Ga, $\beta$, and $\gamma$ subunits) [17]. These $G$ proteins help transduce downstream signaling amplification based on the different functions of each $\mathrm{Ga}$ subunit isoform. Heterotrimeric $\mathrm{G}$ proteins transduce signals by exchanging GDP for GTP on the $\mathrm{Ga}$ subunit in response to ligand dependent activation of the GPCR. The Ga-GTP subunit can then separate from the Gaßy heterocomplex and interact with its downstream signaling effectors. Because different GPCRs interact with a diverse array of intracellular coupled Ga protein isoforms, they can modulate a variety of downstream signaling pathways, and cause unique physiological responses when activated by different stimuli (Figure 1) [18].

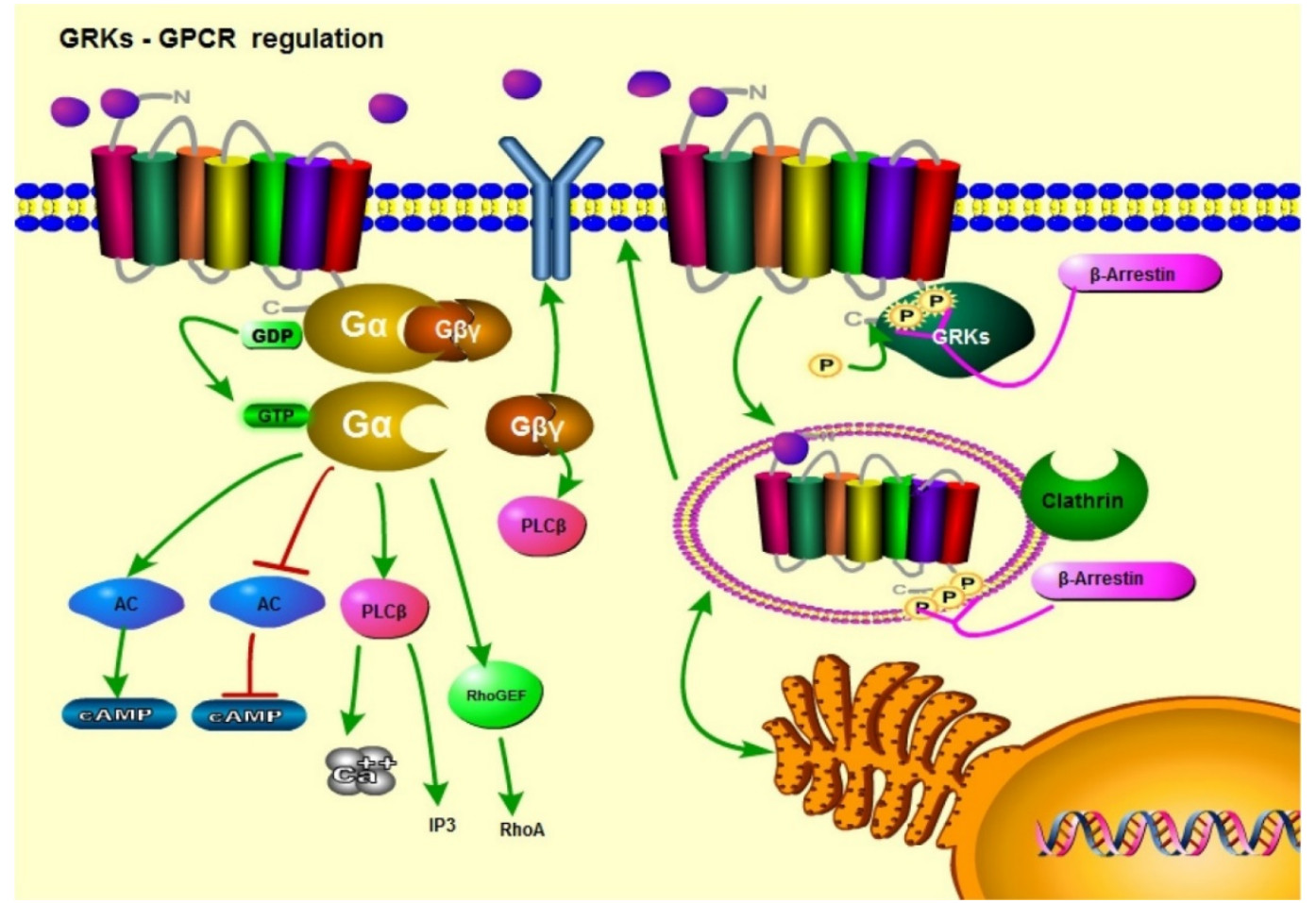

Figure 1. GPCR/GRK cell signaling; a general view. Upon ligand binding, GPCRs activate downstream signaling pathways through their coupled Ga subunits. In response to GPCR conformational changes, G proteins activate downstream targets by converting GDP to GTP. GRKs phosphorylate the intracellular regions of GPCRs. This results in receptor desensitization and arrestin recruitment. Arrestins initiate receptor endocytosis, followed by receptor recycling or degradation. 


\section{GRK family}

The GRK family is comprised of seven serine/threonine kinases. The main function of these proteins is to inhibit activated GPCRs. Mammalian GRKs are classified into three subgroups based on sequence similarity (Figure 2): the rhodopsin kinases (GRK1 [rhodopsin kinase] and GRK7 [cone opsin kinase], the $\beta$-ARK subgroup (GRK2 and GRK3), and the GRK4 subgroup (GRK4, GRK5, and GRK6). In humans, there are four GRK4 splice variants (GRK4-a, GRK4- $\beta$, GRK4- $\gamma$, and GRK4- $\delta$ ), and three GRK6 splice variants (GRK6A, GRK6B, and GRK6C) $[19,20]$.

All mammalian GRKs possess a similar protein structure, with a catalytic domain ( 270 amino acids), an N-terminal domain ( 185 amino acids), and a variable-length C-terminal domain ( 105-230 amino acids). The N-terminal domain contains two conserved motifs for ligand binding and plasma membrane insertion [21, 22]. A single regulator of G-protein signaling (RGS) domain ( 120 amino acids) is located within each of the $\mathrm{N}$ - and C-terminal domains, and both RGS domains contain a kinase catalytic domain (KD). The RGS domains regulate GPCR function via phosphorylation [23-25]. Phosphorylation occurs in response to ligand binding to GPCR. GRK-induced phosphorylation of cytoplasmic serine and threonine residues of GPCR triggers conformational changes in the receptor, revealing high affinity helical binding domains for $\beta$-arrestins. As a result, $\beta$-arrestin binds to the GPCR and inhibits downstream signaling [26]. Because GRKs also belong to protein kinase $A, G$, and C families (AGC), all GRKs share a conserved AGC sequence, which is important for kinase activity [27]. Unlike other GRKs, GRK2 and GRK3 have a pleckstrin homology domain (PH), which is critical for serine/throenine phosphorylation site recognition and termination of $G \beta \gamma$-induced signaling $[28,29]$. In addition, the G $\beta y$ binding site of GRK2 is located in the N-terminal domain, which is involved in GRK2 cell surface localization and termination of $G-\beta Y$ downstream signaling [30]. Furthermore, GRK4 has a phosphatidylinositol-(4,5)-biphosphate (PIP2) motif in its $\mathrm{N}$-terminal that can increase its catalytic kinase activity [31].

GRK4 is predominately expressed in the brain, kidney, testis, and human granulosa cells [32-35]. GRK1 and GRK7 are expressed mainly in retinal cells, where they mediate photo-transduction by phosphorylating rhodopsin receptors [36]. All other GRKs are expressed ubiquitously throughout the body and regulate the functions of a variety of GPCRs [37].

There are many more types of GPCRs than
GRKs, with each GRK interacting with and phosphorylating multiple GPCRs [13]. However, several groups have found that a subset of GRKs show substrate specificity with a select few GPCRs, despite the structural similarity of their domains. Therefore, the physiological roles of each GRK isoform may vary significantly [38]. In agreement, GRKs can find other regions of their targeted GPCR to phosphorylate even when the domain is mutated [39]. The N-terminus of each GRK is highly conserved and critical for GPCR identification. However, how GRKs recognize GPCR conformational changes is still unknown, making its role during GPCR activation unclear [40].

\section{Termination of GPCR signaling}

The major function of GRKs is to mediate signaling termination through phosphorylation of activated GPCRs. The activated GPCR is directly regulated by two major mechanisms involving both GRKs and arrestins, where arrestins are recruited to the GPCR upon phosphorylation by GRKs. These two interacting regulatory proteins terminate GPCR intracellular signal transduction, and control G protein subunit coupling.

The mechanism of GPCR inhibition involves GRK phosphorylation of the intracellular regions of the target GPCR. Arrestins then bind to the phosphorylated GPCR domain to inhibit further G protein activation. This process leads to GPCR desensitization, internalization, and recycling or degradation, which require the recruitment of other proteins such as AP-2 and clathrin. To phosphorylate a ligand-bound GPCR, the GRK must be located at (or translocated to) the plasma membrane, where it forms a complex with the receptor. GRK1, GRK4, GRK5, GRK6, and GRK7 are normally found on the plasma membrane, where they bind and phosphorylate their target receptors. However, GRK2 and GRK3 require further steps in order to localize to the plasma membrane. These two kinases are mainly localized in the cytosol and endoplasmic reticulum. Only upon GPCR activation do they recognize detached G $\beta Y$ subunits and undergo translocation to the plasma membrane to desensitize GPCRs [41]. Once a ligand binds to a GPCR, GRKs sense the intracellular conformational changes as it separates from coupled $\mathrm{G}$ protein subunits. They can then phosphorylate the C-terminus of the target GPCR [42]. Phosphorylation will then induce additional GPCR conformational changes and increase its affinity for arrestins. The binding of arrestins prevents further coupling of $G$ protein subunits and inhibits second messenger signal transduction [43]. Furthermore, GRKs also attenuate GPCR signal transduction by controlling the 
responsiveness of GPCRs to their ligands. This GPCR desensitization allows the cell to distinguish between different types of ligands, such as chemokines, and define the intensity of the cellular response [44]. Previous studies have shown that GRK specificity for a particular GPCR is determined largely based on the ligand bound to the GPCR [45].

\section{GPCR desensitization}

GPCRs amplify signals in response to ligand binding in a dose-dependent manner. Stimulated receptors become less sensitive due to the amount of time they remain in their active form, a phenomenon known as receptor desensitization [24, 46, 47].

In 1983, Sitaramayya et al., demonstrated that GRK1-mediated rhodopsin phosphorylation correlated with cGMP phosphodiesterase activity, and suggested that GRK1 was involved in GPCR desensitization [48]. Thereafter, the importance of pleckstrin homology/G $\beta \gamma$-binding domain in the recruitment of GRK5 during GPCR desensitization was shown in vitro and in vivo. Furthermore, it was found that in the absence of phosphorylation by GRKs, GPCR receptor desensitization was greatly minimized [49]. Overexpression of GRK2 and $\beta$-arrestin in COS-7 cells resulted in GRK2-mediated phosphorylation of the $\beta$-adrenergic receptor, and subsequent recruitment of $\beta$-arrestins [50]. Several in vivo studies have identified co-localization of GRK3 and $\beta$-arrestin-2 in olfactory neuroepithelium in conjunction with dendritic knobs and cilia, and that GRK2 and $\beta$-arrestin-1 are not expressed in these tissues. In response to odorants such as citralva, GRK3-mediated GPCR desensitization was $\beta$-arrestin-2-dependent [51]. With regards to GRK4, no receptor substrate had been identified prior to 2000, when Sallese et al., successfully demonstrated that metabotropic glutamate receptor 1 (mGlu1) signaling could be desensitized by GRK4 in an agonist-dependent manner in HEK293 cells [52]. GRK7 was the last GRK family member identified, and was co-expressed with GRK1 in cone photoreceptor cells [53]. In a zebrafish model, GRK7A deficiency affected cone bleaching adaptation and spontaneous decay, which highlighted the role of GRK7 in GPCR desensitization in scotopic vision [54].

\section{GPCR internalization and degradation}

Internalization is an important mechanism used by cells to regulate GPCR activity and to allow recovery post desensitization. Internalization involves the endocytosis of activated receptors from the plasma membrane, a process that requires GRK activity. The presence of GRKs and their interaction with clathrin in endocytosed vesicles highlights the role they play during receptor internalization [55]. GRKs interact with clathrin through a clathrin-box structure located within the C-terminus normally used to form clathrin-coated pits, and the removal of this domain led to loss of GPCR internalization [56]. For example, silencing of clathrin heavy chain protein inhibited $\beta$-adrenoceptor internalization and phosphorylation, suggesting clathrin may also regulate GRK activity [43, 57].

Goodman et al. previously demonstrated that $\beta$-arrestin subunits 1 and 2 were important in facilitating GPCR internalization [58]. The association of GRKs and arrestins with the C-terminus of various GPCRs led to shuttling of the internalized complex to lysosomes. Interestingly, the binding of $\beta$-arrestin to GPCRs was dependent on GRK phosphorylation of the target receptor. In cases of spontaneous $\beta$-arrestin-independent internalization, the receptor may also be recycled back to the plasma membrane [59].

In the case of $\beta$-adrenoceptor, upon ligand binding, receptor internalization occurred upon recruitment of phosphatidylinositol-4-5-bisphosphate 3-kinase catalytic subunit gamma (PI3KY) to the cell surface [60]. Structural studies of the PI3KY protein suggested its PIK-domain interacted directly with GRK2 [61]. In addition, GRK2 mediated desensitization of $G$ protein-coupled receptor 54 (GPR54) through inositol-(1,4,5)-triphosphate (IP3) formation in response to increasing concentrations of Kisspeptin-10 [62]. Co-transfection of melanocortin 1 receptor (MC1R) and GRK2 or GRK6 in heterologous cells has been shown to impair agonist-dependent cAMP signaling. This indicated that desensitization of MC1R occurred through GRK2 and GRK6 [63].

One of the key roles of GRKs is to regulate the number of GPCRs at the plasma membrane through receptor internalization, which can prevent hyperactivation of the target receptor. Internalized receptors are then degraded by endocytic trafficking to lysosomes. This process can occur either rapidly or over a longer period of time. The internalization and degradation of the $\beta 2$-adrenergic receptor occurs within seconds to minutes upon agonist binding, and can be reversed within minutes after removal of the agonist without new receptor synthesis, a process that is regulated by GRK2. Normally, a rapid reduction of cell surface receptors only temporarily desensitizes the receptor. However, slower regulation of receptor numbers requires receptor endocytosis in combination with synthesis of new receptors, which also involves ubiquitin-dependent protein degradation and GRK3 and GRK6 [64, 65]. 


\section{GRK1/GRK7}

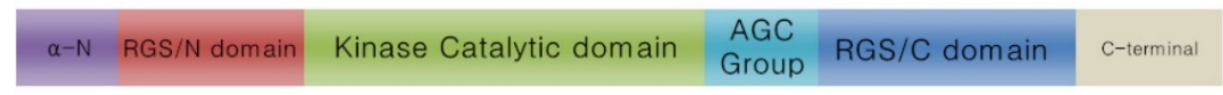

GRK2/GRK3

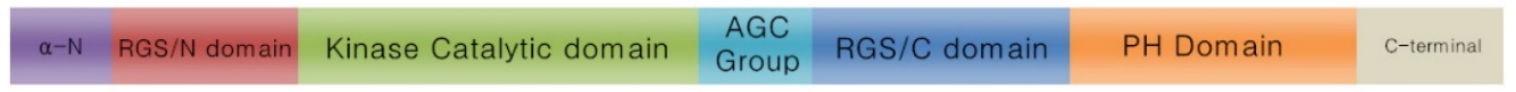

GRK4/GRK5/GRK6

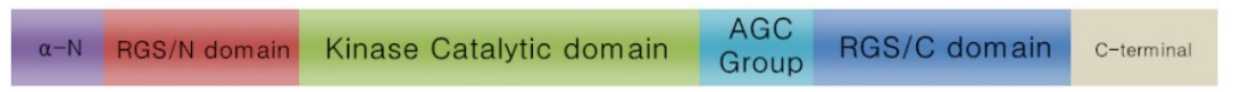

Figure 2. Molecular characteristics of the GRK protein family. All GRKs (60-80KDa) possess a similar molecular structure with an $\alpha$-N-terminal domain followed by an N-terminal Regulator of G protein Signaling domain (RGS/N), which is important for receptor recognition and intracellular membrane anchoring [153, 154]. The protein kinase catalytic domain with a short AGC protein kinase domain is responsible for GRKs catalysis. The C-terminus has more motif variants than the RGS/C domain, which is critical for receptor recognition [14]. Unlike other isoforms, the GRK2 subfamily (GRK2 and GRK3) has a pleckstrin homology domain (PH), which is important for terminating GßY complex-related downstream signaling. The C-terminus length varies among all GRK subtypes ( 105 to 230 AAs).

\section{GPCR biased signaling with GRK}

The discovery of the concept of "biased signaling of GPCR" has revised the classical understanding of GPCR signaling. It is believed that activated GPCR conformation will promote either G-couple proteins or $\beta$-arrestin signaling or both, with a ligand known as "G-protein-biased agonist", " $\beta$-arrestin-biased agonist", or "balanced agonist". The current molecular mechanism of this phenomenon has not been fully revealed yet. The prevailing hypothesis is that GPCR may have a special activated conformational state in response to each ligand leading to different exclusive downstream modulator(s). $\beta$-arrestin does not only serve as the terminator of GPCR signaling, but also acts as a signaling protein, in which the " $\beta$-arrestin-biased signaling" always requires phosphorylated GPCR. Therefore, GRKs are suggested to be critical for therapeutic strategies of $\beta$-arrestin-biased signaling, because GRKs are able to promote high-affinity binding of $\beta$-arrestin to GPCRs. Interestingly, $\beta$-arrestin may have distinct responses to different GRK subtype phosphorylation of the same GPCR. Kelly et al. used $\beta 2$-adrenergic receptor ( $\beta 2 \mathrm{AR}$ ) as an example to demonstrate that different GRK subtypes phosphorylate distinct intracellular sites [38]. After over-expression or silencing of GRK2 or GRK6 through transfection in HEK293 cells, and treatment with either unbiased full agonist (isoproterenol) or $\beta$-arrestin-biased agonist (carvedilol), the author used specific antibodies against 13 phosphorylation sites on the $\beta 2 A R$ to analyze phosphorylated sites by each GRK subtype. The result revealed six (Thr360, Ser364, Ser396, Ser401, Ser407, and Ser411) and two (Ser355 and Ser356) phosphorylation sites for GRK2 and GRK6, respectively. In addition, GRK2 suppressed phosphorylation of the two sites phosphorylated by GRK6. Moreover, GRK6, but not GRK2, is essential for $\beta$-arrestin-dependent ERK1/2 activation. Additional evidence for $\beta 2 \mathrm{AR}$ phosphorylation using PKA assay screening of Ser355 and Ser356 mutants was given by Xiaofang et al. [66]. Their data supported the hypothesis that GRK subtypes might have preferential phosphorylation and trigger unique conformational changes in GPCR. The different phosphorylation pattern therefore directly affects $\beta$-arrestin-dependent functions. Other receptors such as kappa opioid receptor, mu-opioid receptor, angiotensin II receptor type $1 \mathrm{~A}, \mathrm{C}-\mathrm{X}-\mathrm{C}$ chemokine receptor type 4 , and vasopressin type 2 receptor were also reported to exhibit similar properties and showed a contradictory role between GRK2/GRK3 and GRK5/GRK6 in $\beta$-arrestin-mediated signaling [67-72]. However, there are limited studies on the physiological and pharmacological functions of GRK in GPCR-biased signaling. More importantly, because $\beta$-arrestin-biased signaling is involved in the cancer-related signaling pathway, the role of GRK in $\beta$-arrestin-biased signaling in cancer is worthy of attention.

\section{Role of GRKs in non-GPCR signaling pathway}

GRKs play significant roles in non-GPCR-mediated signal transduction by phosphorylating proteins such as receptor tyrosine kinases (RTK). Previous studies have hypothesized a link between GRKs and RTK signaling that not only reveals the diverse role of GRKs in controlling intracellular signaling, but also highlights the potential benefit of targeting GRKs in cancer. In this section, we will discuss several examples of GRK regulation of non-GPCR signaling pathways. 
Early evidence for GRKs as modulators of RTK signaling was based on the observation that ligand activation of epidermal growth factor receptor (EGFR) promoted GRK2 translocation to the plasma membrane to initiate EGFR internalization. EGFR activation of ERK/MAPK via phosphorylation was enhanced in HEK293 cells in response to overexpression of GRK2. These results indicate GRK2 regulated not only EGFR internalization but also its ability to transduce signals [73]. Furthermore, EGF stimulation induced the formation of a GRK2/EGFR complex in a G $\beta \gamma$-dependent manner [74], and pretreatment with the EGFR tyrosine kinase inhibitor, AG 1478, reversed this effect [74]. Other targets of GRK2 include the retinal photo-receptor type 6 cyclic guanosine monophosphate (cGMP) phosphodiesterase (PDE $\gamma$ ), which is found in the internal membranes of retinal photoreceptors, where it reduces cGMP in rod and cone outer segments in response to light [75]. Wan et al. demonstrated that GRK2 targeted PDEY in a complex with c-Src whereby threonine 62 of the PDE $\gamma$ was phosphorylated [76]. This is consistent with earlier reports that Src mediates GRK2 phosphorylation of other plasma membrane proteins [77]. In addition, GRKs mediate the cross talk between RTK and GPCR signaling pathways, such as that which exists between the $\delta$-opioid receptor (DOR), the $\mu$-opioid receptor (MOR), and EGFR [78].

Reduced platelet-derived growth factor receptor (PDGFR) signaling is also found to be associated with GRK2 expression. By modulating the levels of GRK2 expression, Freedman et al. showed that phosphorylation of PDGFR could be altered by GRK2 [79]. It was subsequently found that GRK2 enhanced the ubiquitination of PDGFR leading to its desensitization. In smooth muscle cells, overexpression of full-length GRK2 significantly decreased PDGFR activity in a G $\beta \gamma$-independent manner, but this effect was abrogated in cells expressing a truncated version of GRK2 consisting of only its pleckstrin homology/G $\beta \gamma$-binding domains [80]. However, in the case of GRK5 that lacks pleckstrin homology domain, PDGFR could still be phosphorylated [81]. Moreover, knocking out GRK2 in HEK293 cells strongly enhanced downstream PDGFR signaling, resulting in increased AKT activation [82]. Therefore, the catalytic activity of PDGFR is dependent on the inhibitory activities of GRK2 and GRK5.

Interestingly, an opposite effect was found with regards to the modulation of insulin-like growth factor 1 receptor (IGF-1R) signaling by GRK2, where reduced GRK2 levels inhibited IGF1-R activation. Silencing of GRK2 also enhanced the expression of cyclins and IGF1-R in human hepatocellular carcinoma (HepG2) cells [83], and silencing GRK5 and GRK6 also impaired IGF1-R signaling. However, silencing GRK3 had no effect on the status of IGFR-1 [84]. In this study, GRK2 and GRK6 were found to counteract each other with regards to IGF-1R activation and ERK phosphorylation. It was then suggested that IGFR-1 interacts with both GRK2 and GRK6 to promote $\beta$-arrestin recruitment [84].

Previous studies have illustrated an interaction between vascular endothelial cell growth factor receptor (VEGFR) and GRK in the cardiovascular system and during tumor angiogenesis. Here, GRK5 was shown to regulate VEGF signaling and activation of its downstream effectors (AKT, ERK1/2, and GSK-3) in human coronary artery endothelial cells (HCAECs). However, Sandeep et al. demonstrated that GRK6 depletion enhanced tumorigenesis and metastasis using a GRK6 knock-out mouse model of Lewis lung cancer [85].

There have also been reports of interactions of GRKs with a wide range of other membrane or intracellular proteins, such as nucleophosmin, cyclin-dependent kinase 2 (CDK2), toll-like receptor 4 (TLR4), HSP90, HSP70 interacting protein (Hip), similar mothers against decapentaplegic homolog (SMAD), Rho, synucleins, phosducin, P38, histone deacetylase 5(HDAC5), activin receptor-like kinase 1/5 (ALK1/5), glucose transporter type 4 (GLUT4), mammalian STE20-like kinase 2 (MST2), never in mitosis gene related kinase 2A (NEK2A), tubulin, ezrin, and many other functional proteins [86-102] (summarized in Figure 3). As an example, GRK2 does not directly phosphorylate sphingosine- 1 phosphate receptor (S1PR), but via G-protein-coupled receptor kinase interacting protein-1 (GIT1) to activate the MEK/MAPK/ERK cascade to induce epithelial cell migration [103]. In summary, GRKs play diverse roles in regulating the activity of GPCRs, RTKs, and other receptors to control cell behaviors and maintain homeostasis.

\section{The role of GRK in GPCR transactivation}

In the past decade, GPCR transactivation has further broadened this signaling network, with the two known patterns being from GPCRs to receptor tyrosine kinases (RTK) and receptor serine/threonine kinases (RS/TK). Two mechanisms, ligand-dependent and ligand-independent, are generally accepted for GPCR-RTK transactivation. Membrane-bound matrix metalloproteases (MMPs) play predominant roles in ligand-dependent receptor transactivation. Following GPCR activation, MMP levels increase to enhance the release of membrane-anchored heparin-binding EGF-like growth factor (HB-EGF)[104]. HB-EGF 
further activates EGFR and hence triggers the metastatic and invasive behaviors of cancers. The ligand-independent pathway is based on GPCR activation of Src family proteins, which phosphorylate the intracellular tyrosine residues of RTK to activate the downstream signaling pathway. Examples of GPCR-RTK transactivation in cancers are well summarized in articles written by Almendro et al. [105].

Regarding RS/TK transactivation by GPCR, recent accumulating evidence establishes a GPCR-ROCK-Integrin-TGFBR (ALK5) pathway. Burch et al. properly demonstrated that thrombin activated PAR-1 to transactivate TGF-beta receptor by integrin binding to LLC with conformational alternation that led to TGF-ligand initiation of ALK5 downstream pathway in vascular smooth muscle cells [106]. Also this report supported an early research model on integrin-LLC-ALK [107].
As discussed above, current studies of GRKs involve GPCR-dependent and RTK-dependent mechanisms. As recently evidenced by Kamato et al. using RNA-sequencing in vascular smooth muscle cells, over $50 \%$ GPCR-activated gene expression was accounted for by RTKs and RS/TKs transactivation [108]. Thus, the role of GRK in GPCR-RTK or GPCR-RS/TK transactivation regulation is becoming more apparent and important in cancer research (Figure 4).

\section{The role of GRKs in cancer pathology}

Because GPCR signaling is an important contributor to tumor growth and metastasis, discerning how GRKs regulate GPCR activity in cancer cells may greatly improve our understanding of tumorigenesis and oncogenesis, and help develop novel anticancer therapies. In the following section, we discuss the role of GRKs in cancer progression (an overview is summarized in Table 1).

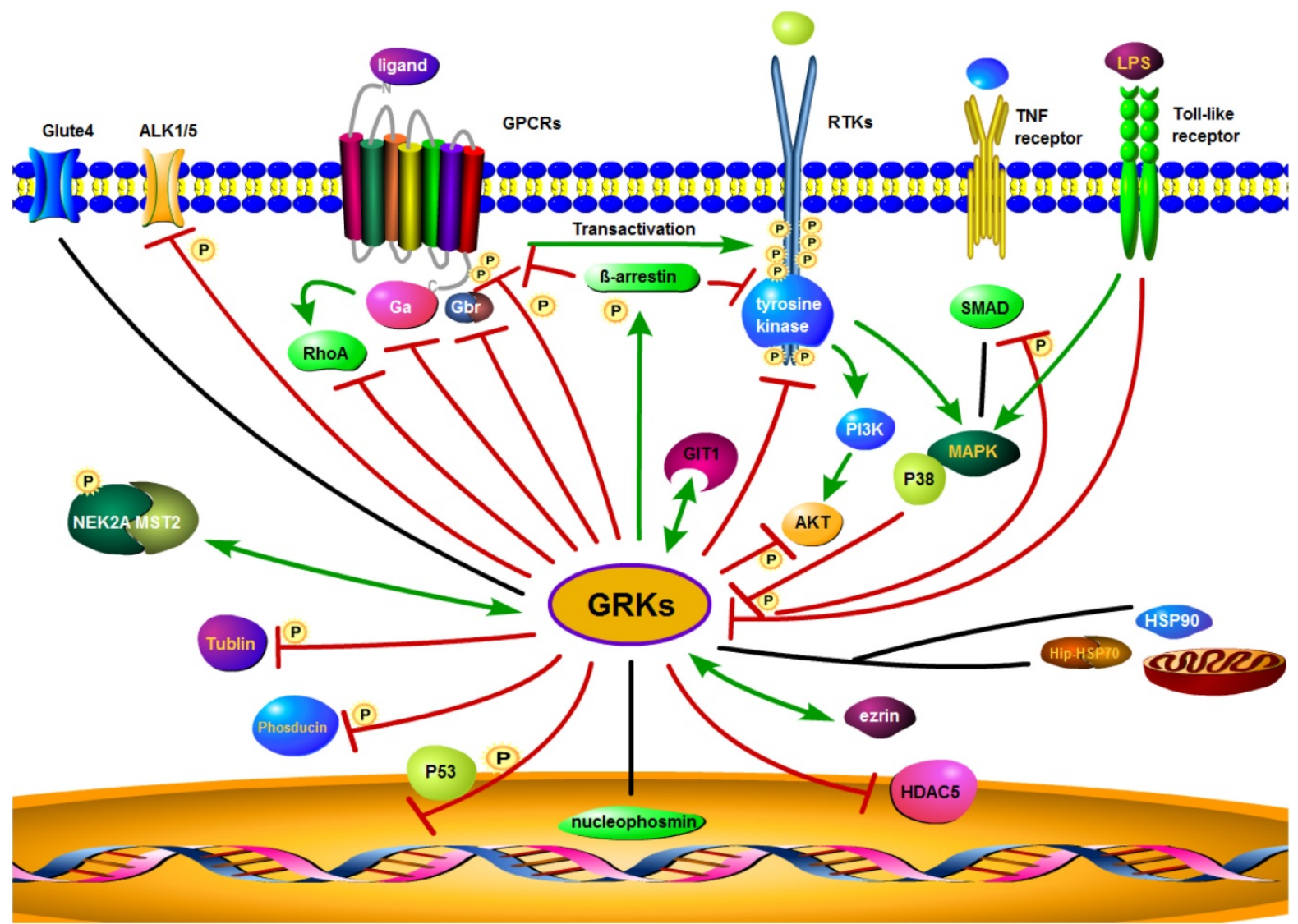

Figure 3. Proposed GRK interaction networks. GRK plays a diverse role in intracellular signaling. GRKs promote $\beta$-arrestin binding to both GPCRs and RTKs. Through their interaction with clathrin coated plasma membrane pits, GRKs mediate receptor internalization, followed by receptor degradation or recycling. GRKs also interact with other intracellular or membrane proteins and modulate interrelated signaling through phosphorylation. Red lines indicate an inhibitory effect of GRKs, while green lines indicate a stimulatory effect. The black lines represent no inhibitory or stimulatory activity. 


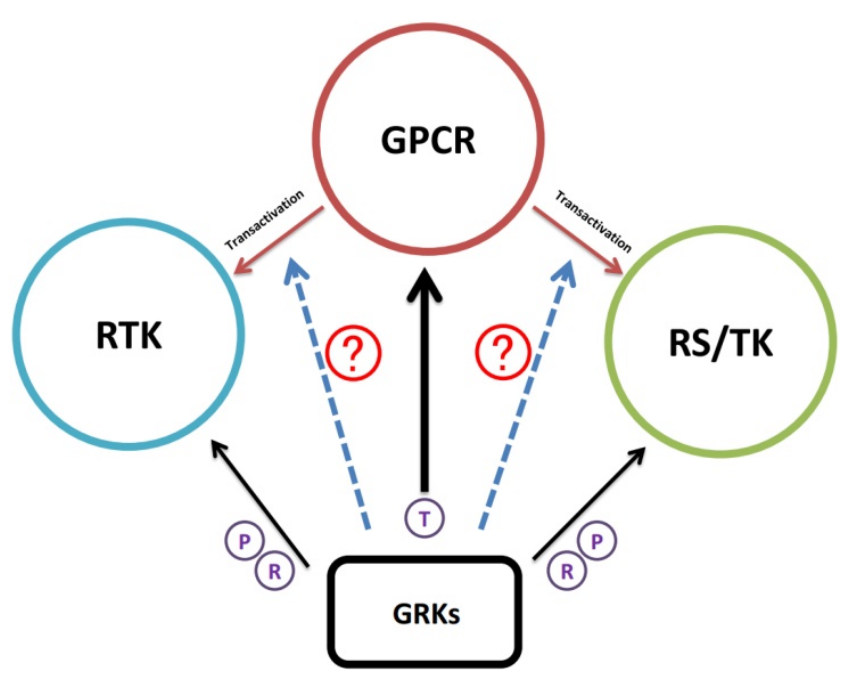

Figure 4. Schematic illustration of GRK regulation research progress. Accumulating evidence suggested that GRKs have the regulatory function in GPCR, RTK, and RS/TK signaling pathways. As GPCR induced transactivation of RTK or RS/TK that further broadened the GPCR network map, the next research area will be certainly turning into the potential functions of GRKs during the transactivation process. Black arrow; studies have confirmed interaction between GRKs and the target substrate. Dotted blue arrow; potential function of GRK in the transactivation of RTK or RS/TK. T in circle; signaling termination. $\mathrm{P}$ in circle; receptor phosphorylation. $\mathrm{R}$ in circle; regulation of receptor activities after interaction.

\section{GRK1 and GRK7}

Because GRK1 and GRK7 are almost exclusively expressed in retinal tissue (cone and rod cells) and phosphorylate opsin GPCRs during visual acquisition, only a handful of cancers have been implicated in dysfunctional GRK1/7 activity. Several groups have shown that GRK1 and GRK7 may be involved in embryogenesis, but also indirectly interact with proteins such as Rho GDP-dissociation inhibitor (RohGDI) and PDEy, both of which have been found to be aberrantly regulated in cancer [109, 110]. Furthermore, reductions in GRK1 activity due to a mutation or deletion causing nonfunctional protein, have been shown to contribute to the onset of Oguchi disease (stationary night blindness Oguchi type-2) [111]. A direct link between reduced GRK1/7 activity and cancer progression has not yet been confirmed. However, GRK1/7 may play a role in cancer-associated retinopathy through its interaction with recoverin (a calcium binding protein) in patients with lung cancer [112].

\section{GRK2}

The role of GRK2 in cancer has been well-characterized. High levels of GRK2 expression are found in differentiated thyroid carcinoma, whereas GRK5 levels are significantly deceased when compared to normal thyroid tissue. The levels of GRK2 protein are correlated with its activity, as it rapidly desensitizes thyroid-stimulating hormone receptor (TSHR), whereas GRK5 inhibits desensitization of this receptor. In thyroid carcinoma, activation of TSHR increased cancer cell proliferation [113]. In human hepatocellular carcinoma HepG2 cells, GRK2 negatively regulates Insulin-like growth factor-1 receptor (IGF1-R) signaling. In GRK2 knockdown cells, reduced GRK2 levels enhanced cyclin and IGF1-R expression. These results highlight the role of GRK2 in suppressing cell cycle progression [83]. Another study using hepatocellular carcinoma cells (HCCs) demonstrated that GRK2 inhibits IGF1 signaling, thereby regulating proliferation and migration [12]. It is generally believed that IGF-1 induces the expression of early growth response protein 1 (EGR1) through reactive oxygen species (ROS)-dependent activation of ERK1/2/JNK and PI3-K/PKB [114]. Modulating the levels of GRK2 expression in HCCs demonstrated that GRK2 regulated EGR1 expression after IGF1 treatment. Altogether, these studies reveal the therapeutic potential of GRK2 by inhibiting IGF1-mediated responses [12, 83, 84]. Moreover, in clinical studies, high GRK2 expression correlated with a high tumor (T) stage and poor survival rates of patients with pancreatic cancer. However, these levels could not be considered as an independent prognostic marker [115].

Yao et al. used a rat osteosarcoma model to evaluate the association between GRK2 and cancer-related pain levels in dorsal root ganglion neurons. Implanted breast carcinosarcoma cells in the tibia resulted in increased expression of GRK2. Nerve growth factor (NGF), together with GRK2, promoted the phosphorylation of opioid receptors, and an increase in pain. In addition, anti-NGF therapies mediated the effects of GRK2 and arrestins to significantly relieve cancer bone pain [116].

GRK2 is also involved in miRNA mediated pathways. MiR-K3, a Kaposi's sarcoma-associated herpesvirus (KSHV) encoding miRNA, facilitates endothelial cell migration and invasion. Interestingly, overexpression of GRK2 in KSHV infected tumor cells reversed this miR-K3-dependent induction. In addition, miR-K3 directly up-regulated GRK2 expression. Moreover, downregulation of miR-K3 by GRK2 inhibited the migration and invasion of KSHV infected HUVEC cells. These results suggest that GRK2 plays a role in suppressing KSHV-associated tumor progression [117].

GRK2 has also been implicated in breast cancer progression. GRK2 levels are elevated in precursor lesions of mammary glands in mouse mammary tumor virus with Her-2 amplification (MMTV-HER2) mice. The expression of GRK2 is also dependent on estrogen receptor alpha (ERa) signaling in human 
breast cancer cell lines. Moreover, increased GRK2 levels may contribute to cellular transformation by promoting mitogenic and anti-apoptotic activities during tumor development. Data obtained from breast cancer patients showed that GRK2 levels were significantly increased in infiltrating ductal carcinomas. This strongly suggests that a relationship exists between GRK2 activity and breast cancer progression [118]. Interestingly, a recent study demonstrated that up-regulation of GRK2 was associated with increased histone deacetylase 6 (HDAC6) expression. GRK2 increased the growth of both luminal and basal breast cancer cells in an HDAC6- and peptidylprolyl-cis/trans-isomerase (Pin1)-dependent manner, and inhibition of GRK2 increased the sensitivity of these cells to commonly used chemotherapeutic compounds. Therefore, the GRK2-HDAC6-Pin1 axis may be a potential therapeutic target for combination therapy [119]. Finally, GRK2 was found to be a negative regulator of CXCR4 (C-X-C chemokine receptor type 4), a chemokine receptor that mediates metastasis and is typically used as an indicator of patient prognosis [120].

GRK2 also plays a role in gastric cancer progression, as studies using human gastric carcinoma MKN-45 cells have shown that GRK2 mediated the homologous desensitization of $\mathrm{H} 2$ receptors in poorly differentiated cancers [121]. Desensitization of $\mathrm{H} 2$ receptors by histamine was inhibited in response to treatment with a GRK2, but not GRK6, antisense phosphorothioateoligo-DNA (PON). This indicates that GRK2 and GRK6 play significantly different roles in modulating $\mathrm{H} 2$ receptor pathways in MKN-45 cells.

With regards to the role of GRK2 in skin cancer, low expression of GRK2 in melanoma cells could enhance cAMP production in response to MC1R agonists. MC1R has been shown to regulate pigmentation and differentiation of epidermal melanocytes and contributed to melanoma progression. This effect was reversed by overexpressing GRK2 and GRK6 [63]. Thus, GRK2 and GRK6 may regulate the development of skin cancer by modulating MC1R signaling.

Table 1. Summary of previous studies investigating GRKs in cancer.

\begin{tabular}{|c|c|c|c|c|}
\hline GRK subtype & Type of cancer & Interacting protein & Function & Ref \\
\hline \multirow[t]{11}{*}{ GRK2 } & thyroidcarcinoma & TSHR & $\downarrow$ proliferation through rapid desensitization & [113] \\
\hline & hepatocellularcarcinoma cell & IGF1-R & $\downarrow$ proliferation and migration & [12] \\
\hline & human hepatocellular carcinoma (HepG2) & IGF1-R & $\downarrow$ cell cycle progression & {$[83]$} \\
\hline & pancreatic cancer & $\mathrm{N} / \mathrm{A}$ & --T-stage and poor survival rate & [115] \\
\hline & breast carcinosarcoma & NGFR & $\downarrow$ bone cancer pain & [116] \\
\hline & $\begin{array}{l}\text { Kaposi's sarcoma-associated herpesvirus } \\
\text { infected tumor cell }\end{array}$ & CXCR2 & $\downarrow$ migration and invasion & [117] \\
\hline & $\begin{array}{l}\text { basal breast cancerwith Her-2 amplification } \\
\text { /infiltrating ductal carcinoma }\end{array}$ & Her-2/ER- $\alpha$ & $\begin{array}{l}\uparrow \text { promoting mitogenic, anti-apoptotic activities } \\
\text {-survival and progression }\end{array}$ & [155] \\
\hline & luminal and basal breast cancer & HDAC6/Pin1 & $\begin{array}{l}\uparrow \text { sensitiveness of breast cancer cells to traditional } \\
\text { chemotherapeutic treatment }\end{array}$ & [119] \\
\hline & breast cancer & CXCR4 & $\downarrow$ metastasis & {$[120]$} \\
\hline & human gastric carcinoma cell line (MKN-45) & $\mathrm{H} 2$ receptor & --poor differentiation & [121] \\
\hline & human breast cancer & $\mathrm{N} / \mathrm{A}$ & $\uparrow$ tumor growth $\downarrow$ angiogenesis & {$[98,122]$} \\
\hline GRK2/5/6 & gastric cancer (SSTW-2) & recoverin & --tumor progression, metastasis & {$[11]$} \\
\hline GRK2/6 & melanoma & melanocortin 1 receptor & --determinant for skin cancer & [63] \\
\hline \multirow[t]{4}{*}{ GRK3 } & breast cancers (MDA-MB-231,MDA-MB-468) & CXCR4 & $\downarrow$ metastasis $\downarrow$ migration & [123] \\
\hline & prostate cancer(PC3) & $\mathrm{N} / \mathrm{A}$ & $\uparrow$ metastasis, tumor progression, angiogenesis & [124] \\
\hline & retinoblastoma(Y-79) & CRF1 receptor & $\uparrow$ stress adaptation & [125] \\
\hline & oral squamouscarcinoma & $\beta 2$-adrenergic receptor & --tumor malignancy and invasion & [126] \\
\hline GRK4 & ovarian malignant granulosa cell tumor & FSHR & $\begin{array}{l}\text {--benign and malignant transformation in tumor } \\
\text { development }\end{array}$ & [35] \\
\hline \multirow[t]{6}{*}{ GRK5 } & glioblastoma & $\mathrm{N} / \mathrm{A}$ & --proliferation rate and WHO Grade & [130] \\
\hline & thyroid carcinoma & TSHR & $\downarrow$ proliferation through slow desensitization & [113] \\
\hline & prostate cancer(PC3) & & $\downarrow$ proliferation, cell cycle & [131] \\
\hline & prostate cancer (PC3, DU145, LNCaP) & Moesin & $\begin{array}{l}\downarrow \text { migration, invasion } \\
\uparrow \text { cell adhesion }\end{array}$ & [132] \\
\hline & prostate cancer & $\mathrm{N} / \mathrm{A}$ & $\uparrow$ tumor growth, invasion and metastasis & [133] \\
\hline & osteosarcoma (U2OS,Saos-2) & P53 & $\downarrow$ cell apoptosis & {$[90]$} \\
\hline \multirow[t]{4}{*}{ GRK6 } & hepatocellular carcinoma & $\mathrm{N} / \mathrm{A}$ & --proliferation maker in early diagnosis & [134] \\
\hline & $\begin{array}{l}\text { hypopharyngeal squamous cell } \\
\text { carcinoma(FaDu) }\end{array}$ & Methylation of GRK6 & $\begin{array}{l}\text {--cancer progression } \\
\downarrow \text { invasion }\end{array}$ & [135] \\
\hline & medulloblastoma & CXCR4/ EGFR/PDGFR-Src & $\uparrow$ migration & [136] \\
\hline & lung cancer & CXCR2 & $\downarrow$ cancer development & {$[85]$} \\
\hline GRK1/7 & & recoverin & --cancer-associated retinopathy & [112] \\
\hline
\end{tabular}

$\mathrm{N} / \mathrm{A}=$ not provided by research $\uparrow$ =increase or promoting related mechanism $\downarrow$ =decrease or diminish related mechanism --=has association with. 
A systematic study by Penela et al. described the regulatory role of GRK2 in tumor vessel formation, as it modulated the proliferation and migration of endothelial cells, and promoted hypoxia and macrophage infiltration during tumor angiogenesis [122]. Rivas et al. further suggested that GRK2 is involved in tumor vessel formation and acts as a regulator of angiogenesis through neovascularization in breast cancer. Using hemizygous GRK2 (GRK2+/-) and endothelium-specific GRK2 knockout mice, it was also shown that reduced GRK2 levels enhanced tumor growth and promoted new blood vessel formation [98].

\section{GRK3}

Fitzhugh et al. firstly showed a role for GRK3 in breast cancer progression as knockdown of this gene in MDA-MB-231 and MDA-MB-468 cells inhibited CXCL12-mediated chemotaxis, suggesting that GRK3 regulates CXCR4 activation of CXCL12 [123]. In vivo, stable knockdown of GKR3 resulted in a high metastatic rate of xenograft breast cancer. Interestingly, according to the study by Billard et al., GRK3 regulated CXCR4 signaling in triple negative and other molecular subtypes of breast cancer [13]. In these studies, GRK3 protein and mRNA expression levels were sensitive to chemokine-mediated migration. This observation was supported by other studies that used extracted data from The Cancer Genome Atlas (TCGA) database. Here, the authors demonstrated that the ratio between GRK3 and CXCR4 may be a key factor in controlling tumor migration and metastasis. Although these authors did not perform in vivo experiments to confirm their findings, they clearly showed that breast cancer metastasis was inhibited by GRK3 through regulation of CXCR4 signaling.

Prostate cancer has also been used as a model to discern the role of GRK3 in metastasis, tumorigenesis, and angiogenesis. $\mathrm{Li}$ et al. found significantly increased migration of endothelial cells in response to elevated expression of GRK3. One group implanted GRK3 knockdown cells into the prostates of SCID mice, and observed enhanced proliferation and metastasis of primary tumors. Microvessel density was modulated by overexpression of GRK3 in primary tumor cells, indicating GRK3 mediated angiogenesis. In agreement, the expression levels of GRK3 were found to be significantly higher in patients with metastatic disease than those with early stage disease [124].

The first report involving GRK3 in retinoblastoma progression dates to 2001. By measuring corticotropin-releasing factor (CRF)- stimulated intracellular cAMP production and PKA signaling pathway activation in Y-79 retinoblastoma cell line, Dautzenberg et al. found that GRK3 controlled desensitization of the CRF1 receptor. Because the CRF1 receptor is known to increase stress adaptation in cancer cells [125], decreased levels of GRK3 may be beneficial to cancer cell survival.

Finally, recent studies have shown that GRK3 is aberrantly expressed in oral squamous carcinoma cells. The mRNA expression levels of GRK3 in tumor samples from patients with oral squamous cell carcinoma were significantly higher than in normal tissues. This study suggests that high expression of GRK3 is associated with oral squamous cell carcinoma tumorigenesis, possibly through the activation of $\beta 2$-adrenergic receptor [126].

\section{GRK4}

GRK4 is expressed primarily in the testis, ovaries, brain, kidney, and myometrium [127]. Due to the low-level expression of GRK4, there are few reports regarding its role in cancer. Several studies have shown that GRK4 modulates arterial angiotensin type 1 (AT1) and dopamine D receptor signaling [128, 129]. In malignant ovarian granulosa cells, the expression of GRK $4 a / \beta$ was also found to be significantly lower than in benign granulosa cells [35]. Silencing of GRK $4 \alpha / \beta$ resulted in decreased kinase activity and impaired follicle-stimulating hormone receptor (FSHR) desensitization. This desensitization may play a crucial role during ovarian granulosa cell transformation, although further investigation is required to fully discern the role of GRK4 in this process.

\section{GRK5}

GRK5 plays various roles during tumorigenesis. The expression of GRK5 is associated with worse prognosis in patients with stage II to IV glioblastoma. Kaur et al. showed that the levels of expression of GRK5 were significantly higher in high-grade primary and recurrent glioblastoma multiforme (GBM) than low-grade glioblastomas. The samples obtained from patients with recurrent diseases had higher GRK5 expression than tumor samples taken prior to recurrence. Knockdown of GRK5 was further shown to decrease the rate of proliferation and expression of stem cell markers in glioblastoma cells derived from a patient with GBM [130]. Note, as previously discussed, GRK2 and GRK5 have opposite roles in thyroid cancer, as GRK2 inhibited the activity of the TSH receptor, while GRK5 promoted its activation [113].

In prostate cancer, it appears that increased expression of GRK5 correlates with tumorigenesis 
and oncogenesis. Silencing of GRK5 inhibited the proliferation of prostate cancer PC3 cells by decreasing the number of cells in G1 and increasing those in the G2/M phase of the cell cycle. These results suggest that GRK5 regulates cell cycle progression in prostate cancer cells [131]. Other studies found that GRK5 was involved in migration, invasion, and cell adhesion of prostate cancer cells through a possible interaction with moesin, a protein known to regulate cell spreading. Overexpression of phosphomimetic moesin-T66D in PC3, DU145, and LNCaP prostate cancer cells significantly reduced cell migration through phosphorylation of moesin by GRK5. Moreover, expression of a phosphorylationdeficient moesin-T66A protein enhanced its activity [132]. In vivo studies have also demonstrated that knockdown of GRK5 in mice with xenografted prostate cancer cells suppressed tumor growth, invasion, and metastasis [132, 133]. Finally, it has been shown that GRK5 could directly phosphorylate P53 tumor suppressor in U2OS and Saos-2 osteosarcoma cells, and promote its degradation, thereby inhibiting tumor cell apoptosis [90].

\section{GRK6}

Studies investigating the function of GRK6 in patients with hepatocellular carcinoma using immunohistochemistry have demonstrated a positive correlation between GRK6 and Ki-67 expression, pathological disease stage, metastasis, and survival rate. These authors hypothesized that GRK6 could be used as a biomarker for the early diagnosis of hepatocellular carcinoma [134]. Furthermore, recoverin, which is functionally associated with GRK6 (as well as GRK2 and GRK5), was aberrantly expressed in SSTW-2 gastric cancer cells [11].

GRK6 mRNA and protein expression was also found to be lower in hypopharyngeal squamous cell carcinomas than normal tissues [135]. Cancer progression appears to be linked to aberrant methylation of GRK6, whose expression correlates with cancer cell invasion and disease stage. In vitro, GRK6 expression levels are elevated and invasion is inhibited in $\mathrm{FaDu}$ cells in response to 5-aza-2'-deoxycytidine [135].

In medulloblastoma cells, PDGFR/Src signaling may mediate GRK6 activity to promote CXCR4 activation of CXCL12 with increased rate of cell migration [136].

GRK6 depletion also enhanced tumorigenesis and metastasis in a Lewis lung cancer mouse model, as MMP-2 and MMP-9 expression was significantly increased in GRK6-/- animals. Pharmacological inhibition of CXCR2 activation abrogated this effect in an NF-kB-dependent manner [85].

\section{GRK inhibitors}

Increased GRK expression levels are correlated with chronic or acute use of GPCR-targeted drugs. In a study investigating GPCR-targeted drug tolerance in the brain, it was shown that increased GRK expression might be responsible for drug resistance $[137,138]$. In addition, various pathological conditions such as heart failure, depression, Alzheimer's disease, and Parkinson's disease are associated with the modulation of endogenous GRK expression [139-143]. Because scientists are beginning to understand more about the biology of GPCR/GRK signaling in cancer, targeting GRKs are emerging as a new anticancer strategy. The most likely methods of developing highly selective GRK inhibitors will be to target their unique kinase domains or decrease GRK expression using selective RNA aptamers [144]. To date, no effective GRK inhibitors have been approved for clinical practice [145]. Because GRKs are a subfamily of AGC kinases, and their kinase domains are relatively similar in structure, nonselective GRK inhibitors may likely cross-react with other AGC kinases [146]. However, one highly selective GRK2 inhibitor known as Takeda Compound 103A that inhibits GRK2 activity 50-fold more than other AGC kinases has been developed by Takeda Pharmaceuticals [147]. Other highly selective drugs such as paroxetine (GRK2), GSK180736A (GRK3), balanol (GRK5), Takeda Compound 101 (GRK2), and sanigivamycin (GRK6) have been widely studied [148]. Although they are reasonably selective for GRKs, they all show cross-reactivity with other kinases. The RNA aptamer, C13, first described by Mayer et al., [149] competes with the alkaloid, staurosporine, for the kinase domain binding on GRK2 without binding to the N- or C-terminus [144, 149]. To our knowledge, the effective inhibitor targeted regions are frequently mutated in the population, limiting the drug's therapeutic potential [150].

\section{Conclusion and perspectives}

In conclusion, GRKs cooperate with arrestins and clathrin to control GPCR signaling. Because GPCRs and RTKs are the primary signal transducers of extracellular stimuli, GRKs act as important regulators to protect cells from overstimulation. Consequently, GRK activity could directly modulate the ability of endocrine hormones to influence the function of cells and tissues. In addition, GRKs help maintain homeostasis by inhibiting signal transduction and facilitating cellular communication in response to extracellular stress.

Recent studies have shown that GRK expression 
levels are implicated in almost every facet of cancer biology, from proliferation, invasion, and migration to metastasis and oncogenic transformation [151]. Significant levels of GRK expression alternation in different cancers indicate that GRKs could be promising molecular targets to be considered to modulate GPCR responsiveness. Due to the heterogeneity of GRK structures, each one appears to play a different role in cancer progression. Investigation of the interesting contradictory roles of each subtype of GRKs may enable development of potent drugs that inhibit some isoforms but activate others for better disease control. GRKs regulate hundreds of unique GPCRs simultaneously, making it complex to fully discern how they modulate cellular signaling. As more GPCR-targeted anticancer therapies are developed, it is important to identify these mechanisms. Our current hypothesis suggests that GRKs primarily act as feedback loops that alter GPCR activity, especially for arrestin-biased signaling. Furthermore, targeting GRKs may result in unintended consequences with regard to the effects of GPCR-targeting drugs, and may induce drug resistance. Because GPCR signaling is becoming a more attractive topic in cancer pharmacology research [152], it is necessary for us to gather a full understanding of these GPCR-GRK interactions to inform more practical and efficient drug design and development. Collectively, pharmacological intervention of GRKs provides us with a novel concept in cancer therapy.

\section{Acknowledgements}

This work and Leo T.O. Lee are supported by FDCT grant (FDCT101/2015/A3) from Macau government, Startup Research Grant (SRG2015-0048-FHS) and Multi-Year Research Grant (MYRG2016-00075-FHS) from University of Macau. L. Sun is supported by National Natural Science Foundation of China (Grant No.81671689).

\section{Competing Interests}

The authors have declared that no competing interest exists.

\section{References}

1. Katritch V, Cherezov V, Stevens RC. Structure-function of the G protein-coupled receptor superfamily. Annu Rev Pharmacol Toxicol. 2013; 53: 531-56.

2. Rosenbaum DM, Rasmussen SG, Kobilka BK. The structure and function of G-protein-coupled receptors. Nature. 2009; 459: 356-63.

3. Julius D, Nathans J. Signaling by sensory receptors. Cold Spring Harb Perspect Biol. 2012; 4: a005991.

4. Zhang R, Xie X. Tools for GPCR drug discovery. Acta Pharmacol Sin. 2012; 33: 372-84.

5. Lappano R, Maggiolini M. G protein-coupled receptors: novel targets for drug discovery in cancer. Nat Rev Drug Discov. 2011; 10: 47-60.

6. Dorsam RT, Gutkind JS. G-protein-coupled receptors and cancer. Nat Rev Cancer. 2007; 7: 79-94.
7. Heifetz A, Schertler GF, Seifert R, Tate CG, Sexton PM, Gurevich VV, et al. GPCR structure, function, drug discovery and crystallography: report from Academia-Industry International Conference (UK Royal Society) Chicheley Hall, 1-2 September 2014. Naunyn Schmiedebergs Arch Pharmacol. 2015; 388: 883-903.

8. Congreve M, Marshall F. The impact of GPCR structures on pharmacology and structure-based drug design. Br J Pharmacol. 2010; 159: 986-96.

9. Hothersall JD, Brown AJ, Dale I, Rawlins P. Can residence time offer a useful strategy to target agonist drugs for sustained GPCR responses? Drug Discov Today. 2016; 21: 90-6.

10. Penela P, Murga C, Ribas C, Lafarga V, Mayor F, Jr. The complex G protein-coupled receptor kinase 2 (GRK2) interactome unveils new physiopathological targets. Br J Pharmacol. 2010; 160: 821-32.

11. Miyagawa $\mathrm{Y}$, Ohguro H, Odagiri H, Maruyama I, Maeda T, Maeda A, et al. Aberrantly expressed recoverin is functionally associated with G-protein-coupled receptor kinases in cancer cell lines. Biochem Biophys Res Commun. 2003; 300: 669-73.

12. Ma Y, Han CC, Huang Q, Sun WY, Wei W. GRK2 overexpression inhibits IGF1-induced proliferation and migration of human hepatocellular carcinoma cells by downregulating EGR1. Oncol Rep. 2016; 35: 3068-74.

13. Billard MJ, Fitzhugh DJ, Parker JS, Brozowski JM, McGinnis MW, Timoshchenko RG, et al. G Protein Coupled Receptor Kinase 3 Regulates Breast Cancer Migration, Invasion, and Metastasis. PLoS One. 2016; 11: e0152856.

14. Gurevich EV, Tesmer JJ, Mushegian A, Gurevich VV. G protein-coupled receptor kinases: more than just kinases and not only for GPCRs. Pharmacol Ther. 2012; 133: 40-69.

15. Pierce KL, Premont RT, Lefkowitz RJ. Seven-transmembrane receptors. Nat Rev Mol Cell Biol. 2002; 3: 639-50.

16. Venkatakrishnan AJ, Deupi X, Lebon G, Tate CG, Schertler GF, Babu MM. Molecular signatures of G-protein-coupled receptors. Nature. 2013; 494: $185-94$

17. Hurowitz EH, Melnyk JM, Chen YJ, Kouros-Mehr H, Simon MI, Shizuya H. Genomic characterization of the human heterotrimeric $\mathrm{G}$ protein alpha, beta, and gamma subunit genes. DNA Res. 2000; 7: 111-20.

18. Neves SR, Ram PT, Iyengar R. G protein pathways. Science. 2002; 296: 1636-9.

19. Premont RT, Macrae AD, Stoffel RH, Chung N, Pitcher JA, Ambrose C, et al. Characterization of the $G$ protein-coupled receptor kinase GRK4. Identification of four splice variants. J Biol Chem. 1996; 271: 6403-10.

20. Hall RA, Spurney RF, Premont RT, Rahman N, Blitzer JT, Pitcher JA, et al. G protein-coupled receptor kinase $6 \mathrm{~A}$ phosphorylates the $\mathrm{Na}(+) / \mathrm{H}(+)$ exchanger regulatory factor via a PDZ domain-mediated interaction. J Biol Chem. 1999; 274: 24328-34

21. Carman CV, Parent JL, Day PW, Pronin AN, Sternweis PM, Wedegaertner PB, et al. Selective regulation of Galpha(q/11) by an RGS domain in the G protein-coupled receptor kinase, GRK2. J Biol Chem. 1999; 274: 34483-92.

22. Sallese M, Mariggio S, D'Urbano E, Iacovelli L, De Blasi A. Selective regulation of $\mathrm{Gq}$ signaling by $\mathrm{G}$ protein-coupled receptor kinase 2: direct interaction of kinase $\mathrm{N}$ terminus with activated galphaq. Mol Pharmacol. 2000; 57: 826-31.

23. Dhami GK, Babwah AV, Sterne-Marr R, Ferguson SS. Phosphorylation-independent regulation of metabotropic glutamate receptor 1 signaling requires g protein-coupled receptor kinase 2 binding to the second intracellular loop. J Biol Chem. 2005; 280: 24420-7.

24. Pitcher JA, Freedman NJ, Lefkowitz RJ. G protein-coupled receptor kinases. Annu Rev Biochem. 1998; 67: 653-92.

25. Eichmann T, Lorenz K, Hoffmann M, Brockmann J, Krasel C, Lohse MJ, et al. The amino-terminal domain of G-protein-coupled receptor kinase 2 is a regulatory Gbeta gamma binding site. J Biol Chem. 2003; 278: 8052-7.

26. Sorkin A, von Zastrow $M$. Endocytosis and signalling: intertwining molecular networks. Nat Rev Mol Cell Biol. 2009; 10: 609-22.

27. Beautrait A, Michalski KR, Lopez TS, Mannix KM, McDonald DJ, Cutter AR, et al. Mapping the putative $G$ protein-coupled receptor (GPCR) docking site on GPCR kinase 2: insights from intact cell phosphorylation and recruitment assays. J Biol Chem. 2014; 289: 25262-75.

28. Gibson TJ, Hyvonen M, Musacchio A, Saraste M, Birney E. PH domain: the first anniversary. Trends Biochem Sci. 1994; 19: 349-53.

29. Wang DS, Shaw R, Winkelmann JC, Shaw G. Binding of PH domains of beta-adrenergic receptor kinase and beta-spectrin to WD40/beta-transducin repeat containing regions of the beta-subunit of trimeric G-proteins. Biochem Biophys Res Commun. 1994; 203: 29-35.

30. Ribas C, Penela P, Murga C, Salcedo A, Garcia-Hoz C, Jurado-Pueyo M, et al. The $\mathrm{G}$ protein-coupled receptor kinase (GRK) interactome: role of GRKs in GPCR regulation and signaling. Biochim Biophys Acta. 2007; 1768: 913-22.

31. Willets JM, Challiss RA, Nahorski SR. Non-visual GRKs: are we seeing the whole picture? Trends Pharmacol Sci. 2003; 24: 626-33.

32. Ambrose C, James M, Barnes G, Lin C, Bates G, Altherr M, et al. A novel G protein-coupled receptor kinase gene cloned from 4p16.3. Hum Mol Genet. 1992; 1: 697-703.

33. Sallese M, Mariggio S, Collodel G, Moretti E, Piomboni P, Baccetti B, et al G protein-coupled receptor kinase GRK4. Molecular analysis of the four isoforms and ultrastructural localization in spermatozoa and germinal cells. J Biol Chem. 1997; 272: 10188-95.

34. Virlon B, Firsov D, Cheval L, Reiter E, Troispoux C, Guillou F, et al. Rat G protein-coupled receptor kinase GRK4: identification, functional expression, 
and differential tissue distribution of two splice variants. Endocrinology. 1998; 139: 2784-95

35. King DW, Steinmetz R, Wagoner HA, Hannon TS, Chen LY, Eugster EA, et al. Differential expression of GRK isoforms in nonmalignant and malignant human granulosa cells. Endocrine. 2003; 22: 135-42.

36. Hargrave PA, McDowell JH. Rhodopsin and phototransduction: a model system for G protein-linked receptors. FASEB J. 1992; 6: 2323-31.

37. Kohout TA, Lefkowitz RJ. Regulation of $G$ protein-coupled receptor kinases and arrestins during receptor desensitization. Mol Pharmacol. 2003; 63: 9-18.

38. Nobles KN, Xiao K, Ahn S, Shukla AK, Lam CM, Rajagopal S, et al. Distinct phosphorylation sites on the beta(2)-adrenergic receptor establish a barcode that encodes differential functions of beta-arrestin. Sci Signal. 2011; 4: ra51.

39. Reiter E, Marion S, Robert F, Troispoux C, Boulay F, Guillou F, et al. Kinase-inactive G-protein-coupled receptor kinases are able to attenuate follicle-stimulating hormone-induced signaling. Biochem Biophys Res Commun. 2001; 282: 71-8.

40. Homan KT, Tesmer JJ. Structural insights into G protein-coupled receptor kinase function. Curr Opin Cell Biol. 2014; 27: 25-31.

41. Lodowski DT, Pitcher JA, Capel WD, Lefkowitz RJ, Tesmer JJ. Keeping G proteins at bay: a complex between $G$ protein-coupled receptor kinase 2 and Gbetagamma. Science. 2003; 300: 1256-62.

42. Black JB, Premont RT, Daaka Y. Feedback regulation of G protein-coupled receptor signaling by GRKs and arrestins. Semin Cell Dev Biol. 2016; 50: 95-104.

43. Penela P, Ribas C, Mayor F, Jr. Mechanisms of regulation of the expression and function of $G$ protein-coupled receptor kinases. Cell Signal. 2003; 15: 973-81.

44. Liu Z, Jiang Y, Li Y, Wang J, Fan L, Scott MJ, et al. TLR4 Signaling augments monocyte chemotaxis by regulating $G$ protein-coupled receptor kinase 2 translocation. J Immunol. 2013; 191: 857-64.

45. Watari K, Nakaya M, Kurose H. Multiple functions of G protein-coupled receptor kinases. J Mol Signal. 2014; 9: 1.

46. Hausdorff WP, Caron MG, Lefkowitz RJ. Turning off the signal: desensitization of beta-adrenergic receptor function. FASEB J. 1990; 4: 2881-9.

47. Pao CS, Benovic JL. Phosphorylation-independent desensitization of G protein-coupled receptors? Sci STKE. 2002; 2002: pe42.

48. Sitaramayya A, Liebman PA. Phosphorylation of rhodopsin and quenching of cyclic GMP phosphodiesterase activation by ATP at weak bleaches. J Biol Chem. 1983; 258: 12106-9.

49. Rockman HA, Choi DJ, Rahman NU, Akhter SA, Lefkowitz RJ, Koch WJ. Receptor-specific in vivo desensitization by the $G$ protein-coupled receptor kinase-5 in transgenic mice. Proc Natl Acad Sci U S A. 1996; 93: 9954-9.

50. Pippig S, Andexinger S, Daniel K, Puzicha M, Caron MG, Lefkowitz RJ, et al. Overexpression of beta-arrestin and beta-adrenergic receptor kinase augment desensitization of beta 2-adrenergic receptors. J Biol Chem. 1993; 268: 3201-8.

51. Dawson TM, Arriza JL, Jaworsky DE, Borisy FF, Attramadal H, Lefkowitz RJ, et al. Beta-adrenergic receptor kinase-2 and beta-arrestin-2 as mediators of odorant-induced desensitization. Science. 1993; 259: 825-9.

52. Sallese M, Salvatore L, D'Urbano E, Sala G, Storto M, Launey T, et al. The G-protein-coupled receptor kinase GRK4 mediates homologous desensitization of metabotropic glutamate receptor 1. FASEB J. 2000; 14: 2569-80.

53. Weiss ER, Ducceschi MH, Horner TJ, Li A, Craft CM, Osawa S. Species-specific differences in expression of G-protein-coupled receptor kinase (GRK) 7 and GRK1 in mammalian cone photoreceptor cells: implications for cone cell phototransduction. J Neurosci. 2001; 21: 9175-84.

54. Rinner O, Makhankov YV, Biehlmaier O, Neuhauss SC. Knockdown of cone-specific kinase GRK7 in larval zebrafish leads to impaired cone response recovery and delayed dark adaptation. Neuron. 2005; 47: 231-42.

55. Ruiz-Gomez A, Mayor F, Jr. Beta-adrenergic receptor kinase (GRK2) colocalizes with beta-adrenergic receptors during agonist-induced receptor internalization. J Biol Chem. 1997; 272: 9601-4.

56. Shiina T, Arai K, Tanabe S, Yoshida N, Haga T, Nagao T, et al. Clathrin box in G protein-coupled receptor kinase 2. J Biol Chem. 2001; 276: 33019-26.

57. Mangmool S, Haga T, Kobayashi H, Kim KM, Nakata H, Nishida M, et al. Clathrin required for phosphorylation and internalization of beta2-adrenergic receptor by $\mathrm{G}$ protein-coupled receptor kinase 2 (GRK2). J Biol Chem. 2006; 281: $31940-9$

58. Goodman OB, Jr., Krupnick JG, Santini F, Gurevich VV, Penn RB, Gagnon $\mathrm{AW}$, et al. Beta-arrestin acts as a clathrin adaptor in endocytosis of the beta2-adrenergic receptor. Nature. 1996; 383: 447-50.

59. Luttrell LM, Lefkowitz RJ. The role of beta-arrestins in the termination and transduction of G-protein-coupled receptor signals. J Cell Sci. 2002; 115: $455-65$.

60. Banday AA, Fazili FR, Lokhandwala MF. Insulin causes renal dopamine D1 receptor desensitization via GRK2-mediated receptor phosphorylation involving phosphatidylinositol 3-kinase and protein kinase C. Am J Physiol Renal Physiol. 2007; 293: F877-84.

61. Naga Prasad SV, Barak LS, Rapacciuolo A, Caron MG, Rockman HA. Agonist-dependent recruitment of phosphoinositide 3-kinase to the membrane by beta-adrenergic receptor kinase 1 . A role in receptor sequestration. J Biol Chem. 2001; 276: 18953-9.

62. Pampillo M, Camuso N, Taylor JE, Szereszewski JM, Ahow MR, Zajac M, et al. Regulation of GPR54 signaling by GRK2 and \{beta\}-arrestin. Mol Endocrinol. 2009; 23: 2060-74.
63. Sanchez-Mas J, Guillo LA, Zanna P, Jimenez-Cervantes C, Garcia-Borron JC. Role of $\mathrm{G}$ protein-coupled receptor kinases in the homologous desensitization of the human and mouse melanocortin 1 receptors. Mol Endocrinol. 2005; 19: 1035-48.

64. von Zastrow M. Role of endocytosis in signalling and regulation of G-protein-coupled receptors. Biochem Soc Trans. 2001; 29: 500-4.

65. Marchese A, Paing MM, Temple BR, Trejo J. G protein-coupled receptor sorting to endosomes and lysosomes. Annu Rev Pharmacol Toxicol. 2008; 48: 601-29.

66. Fan X, Gu X, Zhao R, Zheng O, Li L, Yang W, et al. Cardiac beta2-Adrenergic Receptor Phosphorylation at Ser355/356 Regulates Receptor Internalization and Functional Resensitization. PLoS One. 2016; 11: e0161373.

67. Chiu YT, Chen C, Yu D, Schulz S, Liu-Chen LY. Agonist-dependent and -independent kappa opioid receptor phosphorylation showed distinct phosphorylation patterns and resulted in different cellular outcomes. Mol Pharmacol. 2017.

68. Kuhar JR, Bedini A, Melief EJ, Chiu YC, Striegel HN, Chavkin C. Mu opioid receptor stimulation activates c-Jun $\mathrm{N}$-terminal kinase 2 by distinct arrestin-dependent and independent mechanisms. Cell Signal. 2015; 27: 1799-806.

69. Kim J, Ahn S, Ren XR, Whalen EJ, Reiter E, Wei H, et al. Functional antagonism of different $G$ protein-coupled receptor kinases for beta-arrestin-mediated angiotensin II receptor signaling. Proc Natl Acad Sci U S A. $2005 ; 102$ : 1442-7.

70. Busillo JM, Armando S, Sengupta R, Meucci O, Bouvier M, Benovic JL. Site-specific phosphorylation of CXCR4 is dynamically regulated by multiple kinases and results in differential modulation of CXCR4 signaling. J Biol Chem. 2010; 285: 7805-17.

71. Ren XR, Reiter E, Ahn S, Kim J, Chen W, Lefkowitz RJ. Different G protein-coupled receptor kinases govern $G$ protein and beta-arrestin-mediated signaling of V2 vasopressin receptor. Proc Natl Acad Sci U S A. 2005; 102: 1448-53.

72. Heitzler D, Durand G, Gallay N, Rizk A, Ahn S, Kim J, et al. Competing G protein-coupled receptor kinases balance $G$ protein and beta-arrestin signaling. Mol Syst Biol. 2012; 8: 590.

73. Gao J, Li J, Ma L. Regulation of EGF-induced ERK/MAPK activation and EGFR internalization by $\mathrm{G}$ protein-coupled receptor kinase 2. Acta Biochim Biophys Sin (Shanghai). 2005; 37: 525-31.

74. Gao J, Li J, Chen Y, Ma L. Activation of tyrosine kinase of EGFR induces Gbetagamma-dependent GRK-EGFR complex formation. FEBS Lett. 2005; 579: $122-6$

75. Cote RH. Characteristics of photoreceptor PDE (PDE6): similarities and differences to PDE5. Int J Impot Res. 2004; 16 Suppl 1: S28-33.

76. Wan KF, Sambi BS, Tate R, Waters C, Pyne NJ. The inhibitory gamma subunit of the type 6 retinal cGMP phosphodiesterase functions to link c-Src and G-protein-coupled receptor kinase 2 in a signaling unit that regulates $\mathrm{p} 42 / \mathrm{p} 44$ mitogen-activated protein kinase by epidermal growth factor. J Biol Chem. 2003; 278: 18658-63.

77. Sarnago S, Elorza A, Mayor F, Jr. Agonist-dependent phosphorylation of the G protein-coupled receptor kinase 2 (GRK2) by Src tyrosine kinase. J Biol Chem. 1999; 274: 34411-6.

78. Chen $\mathrm{Y}$, Long $\mathrm{H}, \mathrm{Wu} \mathrm{Z}$, Jiang $\mathrm{X}$, Ma L. EGF transregulates opioid receptors through EGFR-mediated GRK2 phosphorylation and activation. Mol Biol Cell. 2008; 19: 2973-83.

79. Freedman NJ, Kim LK, Murray JP, Exum ST, Brian L, Wu JH, et al. Phosphorylation of the platelet-derived growth factor receptor-beta and epidermal growth factor receptor by G protein-coupled receptor kinase-2. Mechanisms for selectivity of desensitization. J Biol Chem. 2002; 277: 48261-9.

80. Peppel K, Jacobson A, Huang X, Murray JP, Oppermann M, Freedman NJ. Overexpression of $G$ protein-coupled receptor kinase- 2 in smooth muscle cells attenuates mitogenic signaling via $G$ protein-coupled and platelet-derived growth factor receptors. Circulation. 2000; 102: 793-9.

81. Cai X, Wu JH, Exum ST, Oppermann M, Premont RT, Shenoy SK, et al. Reciprocal regulation of the platelet-derived growth factor receptor-beta and $\mathrm{G}$ protein-coupled receptor kinase 5 by cross-phosphorylation: effects on catalysis. Mol Pharmacol. 2009; 75: 626-36.

82. Hildreth KL, Wu JH, Barak LS, Exum ST, Kim LK, Peppel K, et al. Phosphorylation of the platelet-derived growth factor receptor-beta by $\mathrm{G}$ protein-coupled receptor kinase- 2 reduces receptor signaling and interaction with the $\mathrm{Na}(+) / \mathrm{H}(+)$ exchanger regulatory factor. J Biol Chem. 2004; 279: 41775-82.

83. Wei Z, Hurtt R, Gu T, Bodzin AS, Koch WJ, Doria C. GRK2 negatively regulates IGF-1R signaling pathway and cyclins' expression in HepG2 cells. J Cell Physiol. 2013; 228: 1897-901.

84. Zheng $\mathrm{H}$, Worrall $\mathrm{C}$, Shen $\mathrm{H}$, Issad $\mathrm{T}$, Seregard S, Girnita A, et al. Selective recruitment of $G$ protein-coupled receptor kinases (GRKs) controls signaling of the insulin-like growth factor 1 receptor. Proc Natl Acad Sci U S A. 2012; 109: 7055-60.

85. Raghuwanshi SK, Smith N, Rivers EJ, Thomas AJ, Sutton N, Hu Y, et al. G Protein-Coupled Receptor Kinase 6 Deficiency Promotes Angiogenesis, Tumor Progression, and Metastasis. The Journal of Immunology. 2013; 190: 5329-36.

86. Barker BL, Benovic JL. G protein-coupled receptor kinase 5 phosphorylation of hip regulates internalization of the chemokine receptor CXCR4. Biochemistry. 2011; 50: 6933-41. 
87. Penela P, Rivas V, Salcedo A, Mayor F, Jr. G protein-coupled receptor kinase 2 (GRK2) modulation and cell cycle progression. Proc Natl Acad Sci U S A. 2010; 107: 1118-23.

88. Ho J, Cocolakis E, Dumas VM, Posner BI, Laporte SA, Lebrun JJ. The G protein-coupled receptor kinase- 2 is a TGFbeta-inducible antagonist of TGFbeta signal transduction. EMBO J. 2005; 24: 3247-58.

89. Carman CV, Som T, Kim CM, Benovic JL. Binding and phosphorylation of tubulin by $\mathrm{G}$ protein-coupled receptor kinases. J Biol Chem. 1998; 273 : 20308-16.

90. Chen X, Zhu H, Yuan M, Fu J, Zhou Y, Ma L. G-protein-coupled receptor kinase 5 phosphorylates p53 and inhibits DNA damage-induced apoptosis. J Biol Chem. 2010; 285: 12823-30.

91. Pronin AN, Morris AJ, Surguchov A, Benovic JL. Synucleins are a novel class of substrates for G protein-coupled receptor kinases. J Biol Chem. 2000; 275: 26515-22.

92. Ruiz-Gomez A, Humrich J, Murga C, Quitterer U, Lohse MJ, Mayor F, Jr. Phosphorylation of phosducin and phosducin-like protein by G protein-coupled receptor kinase 2. J Biol Chem. 2000; 275: 29724-30.

93. Cant SH, Pitcher JA. G protein-coupled receptor kinase 2-mediated phosphorylation of ezrin is required for $G$ protein-coupled receptor-dependent reorganization of the actin cytoskeleton. Mol Biol Cell. 2005; 16: 3088-99.

94. Martini JS, Raake P, Vinge LE, DeGeorge BR, Jr., Chuprun JK, Harris DM, et al. Uncovering $G$ protein-coupled receptor kinase-5 as a histone deacetylase kinase in the nucleus of cardiomyocytes. Proc Natl Acad Sci U S A. 2008; 105: 12457-62.

95. So $\mathrm{CH}$, Michal AM, Mashayekhi R, Benovic JL. G protein-coupled receptor kinase 5 phosphorylates nucleophosmin and regulates cell sensitivity to polo-like kinase 1 inhibition. J Biol Chem. 2012; 287: 17088-99.

96. Barthet G, Carrat G, Cassier E, Barker B, Gaven F, Pillot M, et al. Beta-arrestin1 phosphorylation by GRK5 regulates G protein-independent 5-HT4 receptor signalling. EMBO J. 2009; 28: 2706-18.

97. Mardin BR, Agircan FG, Lange C, Schiebel E. Plk1 controls the Nek2A-PP1gamma antagonism in centrosome disjunction. Curr Biol. 2011; 21: 1145-51.

98. Rivas V, Carmona R, Munoz-Chapuli R, Mendiola M, Nogues L, Reglero C, et al. Developmental and tumoral vascularization is regulated by G protein-coupled receptor kinase 2. J Clin Invest. 2013; 123: 4714-30.

99. Robinson JD, Pitcher JA. G protein-coupled receptor kinase 2 (GRK2) is a Rho-activated scaffold protein for the ERK MAP kinase cascade. Cell Signal. 2013; 25: 2831-9.

100. Zhang Y, Matkovich SJ, Duan X, Gold JI, Koch WJ, Dorn GW, 2nd. Nuclear effects of G-protein receptor kinase 5 on histone deacetylase 5-regulated gene transcription in heart failure. Circ Heart Fail. 2011; 4: 659-68.

101. Dehvari N, Hutchinson DS, Nevzorova J, Dallner OS, Sato M, Kocan M, et al. beta(2)-Adrenoceptors increase translocation of GLUT4 via GPCR kinase sites in the receptor C-terminal tail. Br J Pharmacol. 2012; 165: 1442-56.

102. Patial S, Saini Y, Parvataneni S, Appledorn DM, Dorn GW, 2nd, Lapres JJ, et al. Myeloid-specific GPCR kinase-2 negatively regulates NF-kappaB1p105-ERK pathway and limits endotoxemic shock in mice. J Cell Physiol. 2011; 226: 627-37.

103. Penela P, Ribas C, Aymerich I, Eijkelkamp N, Barreiro O, Heijnen CJ, et al. G protein-coupled receptor kinase 2 positively regulates epithelial cell migration. EMBO J. 2008; 27: 1206-18.

104. Wang Z. Transactivation of Epidermal Growth Factor Receptor by G Protein-Coupled Receptors: Recent Progress, Challenges and Future Research. Int J Mol Sci. 2016; 17.

105. Almendro V, Garcia-Recio S, Gascon P. Tyrosine kinase receptor transactivation associated to $\mathrm{G}$ protein-coupled receptors. Curr Drug Targets. 2010; 11: 1169-80.

106. Burch ML, Getachew R, Osman N, Febbraio MA, Little PJ. Thrombin-mediated proteoglycan synthesis utilizes both protein-tyrosine kinase and serine/threonine kinase receptor transactivation in vascular smooth muscle cells. J Biol Chem. 2013; 288: 7410-9.

107. Munger JS, Huang X, Kawakatsu H, Griffiths MJ, Dalton SL, Wu J, et al. The integrin alpha $\mathrm{v}$ beta 6 binds and activates latent TGF beta 1: a mechanism for regulating pulmonary inflammation and fibrosis. Cell. 1999; 96: 319-28.

108. Kamato D, Bhaskarala VV, Mantri N, Oh TG, Ling D, Janke R, et al. RNA sequencing to determine the contribution of kinase receptor transactivation to $\mathrm{G}$ protein coupled receptor signalling in vascular smooth muscle cells. PLoS One. 2017; 12: e0180842.

109. Zhang H, Li S, Doan T, Rieke F, Detwiler PB, Frederick JM, et al. Deletion of PrBP/delta impedes transport of GRK1 and PDE6 catalytic subunits to photoreceptor outer segments. Proc Natl Acad Sci U S A. 2007; 104: 8857-62.

110. Zhang H, Frederick JM, Baehr W. Unc119 gene deletion partially rescues the GRK1 transport defect of Pde6d (- /-) cones. Adv Exp Med Biol. 2014; 801: 487-93.

111. Yamamoto S, Sippel KC, Berson EL, Dryja TP. Defects in the rhodopsin kinase gene in the Oguchi form of stationary night blindness. Nat Genet. 1997; 15: $175-8$.

112. Maeda T, Maeda A, Maruyama I, Ogawa KI, Kuroki Y, Sahara H, et al. Mechanisms of photoreceptor cell death in cancer-associated retinopathy. Invest Ophthalmol Vis Sci. 2001; 42: 705-12.
113. Metaye T, Menet E, Guilhot J, Kraimps JL. Expression and activity of $g$ protein-coupled receptor kinases in differentiated thyroid carcinoma. J Clin Endocrinol Metab. 2002; 87: 3279-86.

114. Youreva V, Srivastava AK. Early Growth Response Protein-1 Expression by Insulin-Like Growth Factor-1 Requires ROS-Dependent Activation of ERK1/2 and PKB Pathways in Vascular Smooth Muscle Cells. J Cell Biochem. 2016; 117: $152-62$.

115. Zhou L, Wang MY, Liang ZY, Zhou WX, You L, Pan BJ, et al. G-protein-coupled receptor kinase 2 in pancreatic cancer: clinicopathologic and prognostic significance. Hum Pathol. 2016; 56: 171-7.

116. Peng $Y$, bin WZ. Expression of GRK2 and $\beta$-arrestin2 in the dorsal root ganglion neurons and the regulated effect by nerve growth factor in rats with bone cancer pain. Chinese Journal of Cancer Prevention and Treatment. 2011; 18: 4 .

117. Hu M, Wang C, Li W, Lu W, Bai Z, Qin D, et al. A KSHV microRNA Directly Targets G Protein-Coupled Receptor Kinase 2 to Promote the Migration and Invasion of Endothelial Cells by Inducing CXCR2 and Activating AKT Signaling. PLoS Pathog. 2015; 11: e1005171.

118. Nogues L, Salcedo A, Mendiola M, Hardisson D, Mayor F, Penela P. G Protein-coupled Receptor Kinase 2 (GRK2) Contributes to Cellular Transformation and Breast Tumor Progression. Eur J Cancer. 2012; 48: S80-S1.

119. Nogues L, Reglero C, Rivas V, Salcedo A, Lafarga V, Neves M, et al. G Protein-coupled Receptor Kinase 2 (GRK2) Promotes Breast Tumorigenesis Through a HDAC6-Pin1 Axis. EBioMedicine. 2016.

120. Mukherjee D, Zhao J. The Role of chemokine receptor CXCR4 in breast cancer metastasis. Am J Cancer Res. 2013; 3: 46-57.

121. Nakata H, Kinoshita Y, Kishi K, Fukuda H, Kawanami C, Matsushima Y, et al. Involvement of beta-adrenergic receptor kinase-1 in homologous desensitization of histamine $\mathrm{H} 2$ receptors in human gastric carcinoma cell line MKN-45. Digestion. 1996; 57: 406-10.

122. Rivas V, Chapuli RM, Mayor F, Penela P. 346 Role of GRK2 in Developing Vasculature and Pathological Angiogenesis. Eur J Cancer. 2012;48: S84.

123. Fitzhugh DJ, McGinnis MW, Timoshchenko R, Lininger R, Demore N, Serody J, et al. G Protein Coupled Receptor Kinase 3 (GRK3) Negatively Regulates CXCL12/CXCR4 Signaling and Tumor Migration in Breast Cancer. Journal of Allergy and Clinical Immunology. 2011;127: AB230.

124. Li W, Ai N, Wang S, Bhattacharya N, Vrbanac V, Collins M, et al. GRK3 is essential for metastatic cells and promotes prostate tumor progression. Proc Natl Acad Sci U S A. 2014; 111: 1521-6.

125. Dautzenberg FM, Braun S, Hauger RL. GRK3 mediates desensitization of CRF1 receptors: a potential mechanism regulating stress adaptation. Am J Physiol Regul Integr Comp Physiol. 2001; 280: R935-46.

126. Perez-Sayans M, Somoza-Martin JM, Barros-Angueira F, Gayoso-Diz P, Otero-Rey EM, Gandra-Rey JM, et al. Activity of beta2-adrenergic receptor in oral squamous cell carcinoma is mediated by overexpression of the ADRBK2 gene: a pilot study. Biotech Histochem. 2012; 87: 179-86.

127. Brenninkmeijer CB, Price SA, Lopez Bernal A, Phaneuf S. Expression of G-protein-coupled receptor kinases in pregnant term and non-pregnant human myometrium. J Endocrinol. 1999; 162: 401-8.

128. Chen K, Fu C, Chen C, Liu L, Ren H, Han Y, et al. Role of GRK4 in the regulation of arterial AT1 receptor in hypertension. Hypertension. 2014; 63: $289-96$.

129. Villar VA, Jones JE, Armando I, Palmes-Saloma C, Yu P, Pascua AM, et al. G protein-coupled receptor kinase 4 (GRK4) regulates the phosphorylation and function of the dopamine D3 receptor. J Biol Chem. 2009; 284: 21425-34.

130. Kaur G, Kim J, Kaur R, Tan I, Bloch O, Sun MZ, et al. G-protein coupled receptor kinase (GRK)-5 regulates proliferation of glioblastoma-derived stem cells. J Clin Neurosci. 2013; 20: 1014-8.

131. Malbon CC. Frizzleds: new members of the superfamily of G-protein-coupled receptors. Front Biosci. 2004; 9: 1048-58.

132. Chakraborty PK, Zhang Y, Coomes AS, Kim WJ, Stupay R, Lynch LD, et al. G protein-coupled receptor kinase GRK5 phosphorylates moesin and regulates metastasis in prostate cancer. Cancer Res. 2014; 74: 3489-500.

133. Kim JI, Chakraborty P, Wang Z, Daaka Y. G-protein coupled receptor kinase 5 regulates prostate tumor growth. J Urol. 2012; 187: 322-9.

134. Li YP. GRK6 expression in patients with hepatocellular carcinoma. Asian Pac J Trop Med. 2013; 6: 220-3

135. Qiu X, Chen J, Zhang Z, You Y, Wang Z. Aberrant GRK6 promoter methylation is associated with poor prognosis in hypopharyngeal squamous cell carcinoma. Oncol Rep. 2016; 35: 1027-33.

136. Yuan L, Zhang H, Liu J, Rubin JB, Cho YJ, Shu HK, et al. Growth factor receptor-Src-mediated suppression of GRK6 dysregulates CXCR4 signaling and promotes medulloblastoma migration. Mol Cancer. 2013; 12: 18.

137. Hurle MA. Changes in the expression of $G$ protein-coupled receptor kinases and beta-arrestin 2 in rat brain during opioid tolerance and supersensitivity. J Neurochem 2001: 77: 486-92.

138. Diaz A, Pazos A, Florez J, Ayesta FJ, Santana V, Hurle MA. Regulation of mu-opioid receptors, G-protein-coupled receptor kinases and beta-arrestin 2 in the rat brain after chronic opioid receptor antagonism. Neuroscience. 2002; 112: 345-53.

139. Bychkov ER, Gurevich VV, Joyce JN, Benovic JL, Gurevich EV. Arrestins and two receptor kinases are upregulated in Parkinson's disease with dementia. Neurobiol Aging. 2008; 29: 379-96. 
140. Suo Z, Cox AA, Bartelli N, Rasul I, Festoff BW, Premont RT, et al. GRK5 deficiency leads to early Alzheimer-like pathology and working memory impairment. Neurobiol Aging. 2007; 28: 1873-88.

141. Ungerer M, Parruti G, Bohm M, Puzicha M, DeBlasi A, Erdmann E, et al. Expression of beta-arrestins and beta-adrenergic receptor kinases in the failing human heart. Circ Res. 1994; 74: 206-13.

142. Grange-Midroit M, Garcia-Sevilla JA, Ferrer-Alcon M, La Harpe R, Huguelet P, Guimon J. Regulation of GRK 2 and 6, beta-arrestin-2 and associated proteins in the prefrontal cortex of drug-free and antidepressant drug-treated subjects with major depression. Brain Res Mol Brain Res. 2003; 111: 31-41.

143. Taneja M, Salim S, Saha K, Happe HK, Qutna N, Petty F, et al. Differential effects of inescapable stress on locus coeruleus GRK3, alpha2-adrenoceptor and CRF1 receptor levels in learned helpless and non-helpless rats: a potential link to stress resilience. Behav Brain Res. 2011; 221: 25-33.

144. Tesmer VM, Lennarz S, Mayer G, Tesmer JJ. Molecular mechanism for inhibition of $g$ protein-coupled receptor kinase 2 by a selective RNA aptamer. Structure. 2012; 20: 1300-9.

145. Homan KT, Tesmer JJ. Molecular basis for small molecule inhibition of G protein-coupled receptor kinases. ACS Chem Biol. 2015; 10: 246-56.

146. Waldschmidt HV, Homan KT, Cruz-Rodriguez O, Cato MC, Waninger-Saroni J, Larimore KM, et al. Structure-Based Design, Synthesis, and Biological Evaluation of Highly Selective and Potent G Protein-Coupled Receptor Kinase 2 Inhibitors. J Med Chem. 2016; 59: 3793-807.

147. Thal DM, Yeow RY, Schoenau C, Huber J, Tesmer JJ. Molecular mechanism of selectivity among G protein-coupled receptor kinase 2 inhibitors. Mol Pharmacol. 2011; 80: 294-303.

148. Thal DM, Homan KT, Chen J, Wu EK, Hinkle PM, Huang ZM, et al. Paroxetine is a direct inhibitor of $\mathrm{g}$ protein-coupled receptor kinase 2 and increases myocardial contractility. ACS Chem Biol. 2012; 7: 1830-9.

149. Mayer G, Wulffen B, Huber C, Brockmann J, Flicke B, Neumann L, et al. An RNA molecule that specifically inhibits G-protein-coupled receptor kinase 2 in vitro. RNA. 2008; 14: 524-34.

150. Zalewska M, Siara M, Sajewicz W. G protein-coupled receptors: abnormalities in signal transmission, disease states and pharmacotherapy. Acta Pol Pharm. 2014; 71: 229-43.

151. Nogues L, Palacios-Garcia J, Reglero C, Rivas V, Neves M, Ribas C, et al. G protein-coupled receptor kinases (GRKs) in tumorigenesis and cancer progression: GPCR regulators and signaling hubs. Semin Cancer Biol. 2017.

152. Bar-Shavit R, Maoz M, Kancharla A, Nag JK, Agranovich D Grisaru-Granovsky S, et al. G Protein-Coupled Receptors in Cancer. Int J Mol Sci. 2016; 17.

153. Murga C, Ruiz-Gomez A, Garcia-Higuera I, Kim CM, Benovic JL, Mayor F, Jr. High affinity binding of beta-adrenergic receptor kinase to microsomal membranes. Modulation of the activity of bound kinase by heterotrimeric $G$ protein activation. J Biol Chem. 1996; 271: 985-94.

154. Huang CC, Orban T, Jastrzebska B, Palczewski K, Tesmer JJ. Activation of G protein-coupled receptor kinase 1 involves interactions between its $\mathrm{N}$-terminal region and its kinase domain. Biochemistry. 2011; 50: 1940-9.

155. Nogues L, Salcedo A, Mendiola M, Hardisson D, Mayor F, Penela P. 330 G Protein-coupled Receptor Kinase 2 (GRK2) Contributes to Cellular Transformation and Breast Tumor Progression. Eur J Cancer. 2012;48: S80-S1. 